\title{
Cool-Season Precipitation Patterns Associated with Teleconnection Interactions in the United States*
}

\author{
ERIKA K. WISE \\ Department of Geography, University of North Carolina at Chapel Hill, Chapel Hill, North Carolina \\ MELISSA L. WRZESIEN \\ School of Earth Sciences, The Ohio State University, Columbus, Ohio \\ MATTHEW P. DANNENBERG \\ Department of Geography, University of North Carolina at Chapel Hill, Chapel Hill, North Carolina \\ DAVID L. MCGINNIS \\ Montana State University Billings, Billings, Montana
}

(Manuscript received 26 February 2014, in final form 3 August 2014)

\begin{abstract}
Seasonal climate forecasts are regularly published to provide decision makers with insights on upcoming climate conditions. Precipitation forecasts, in particular, are useful for fields such as agriculture and water resources. Projections frequently cite a single climate oscillation such as El Niño-Southern Oscillation (ENSO) or the North Atlantic Oscillation (NAO) when suggesting whether a region will be wetter or drier than normal. The complex climate system is composed of a multitude of simultaneous oceanic and atmospheric oscillations, however. Through the study of five atmospheric-pressure-based oscillations, their interactions, and associated precipitation values, this research demonstrates the wide variety of precipitation patterns that can arise when different phases of prominent climate modes occur. Results show that incorporating other Northern Hemisphere teleconnections can dampen or shift expected ENSO and NAO impact patterns. These results indicate that seasonal precipitation projections may be improved by incorporating multiple, regionally important teleconnection indices into the forecast.
\end{abstract}

\section{Introduction}

Seasonal precipitation forecasts provide a projection of upcoming conditions. A wide range of sectors, including agriculture (Jones et al. 2000; Agrawala et al. 2001; Meinke and Stone 2005; Hansen et al. 2006), human health (Thomson et al. 2006; Thomson 2010; Rodó et al. 2013), water resources (Wedgbrow et al. 2002;

\footnotetext{
* Supplemental information related to this paper is available at the Journals Online website: http://dx.doi.org/10.1175/JAMCD-14-0040.s1.

Corresponding author address: Erika K. Wise, Dept. of Geography, University of North Carolina at Chapel Hill, Saunders Hall, Campus Box 3220, Chapel Hill, NC 27599-3220.

E-mail: ekwise@email.unc.edu
}

Werritty 2002; Sinha and Sankarasubramanian 2013), and energy (Cherry et al. 2005), use climate forecasts to plan management strategies. Oceanic and atmospheric oscillations have far-reaching, teleconnected climate impacts and are incorporated into climate forecasts. Knowledge of a single climatic mode, such as El NiñoSouthern Oscillation (ENSO), can improve our understanding of seasonal conditions expected at many worldwide locations. Because of its global impact, climate forecasts frequently cite ENSO when projecting whether a region will experience conditions that are wetter or drier than normal. The Climate Prediction Center (CPC) cites ENSO as the primary factor influencing their seasonal forecasts (http://www.cpc.ncep. noaa.gov/products/predictions/90day/fxus05.html). Other atmospheric patterns [such as the North Atlantic Oscillation (NAO)] are used in the CPC climate outlook, 
although mainly in temperature predictions. Following record-low NAO values in recent winters and corresponding record snowfall (e.g., winter of 2010 in Washington, D.C.; Baltimore, Maryland; and Philadelphia, Pennsylvania), researchers have increasingly explored the possible value of incorporating NAO conditions into seasonal forecasts (Fereday et al. 2012; Kalra et al. 2013), and media outlets have begun discussing NAO in addition to ENSO (e.g., Revkin 2010; Roylance 2010).

NAO, ENSO, and other important modes of climate variability do not occur in isolation. While El Niño is typically associated with increased precipitation in the southern United States (e.g., Redmond and Koch 1991; Barnston et al. 1999), the presence of other teleconnection patterns can strengthen or weaken the expected precipitation signal. For example, the record eastern North American winter snowfalls of 2009/10 were linked to the interaction of El Niño with a negative NAO (Seager et al. 2010). Many studies have examined teleconnection impacts on precipitation anomalies in the United States on the basis of an individual index [e.g., the Pacific-North American (PNA) pattern (Henderson and Robinson 1994) and ENSO (Dai and Wigley 2000)] or the joint impacts of ocean-atmosphere oscillations, particularly ENSO and the Pacific decadal oscillation (Gutzler et al. 2002; McCabe and Dettinger 2002; Hidalgo and Dracup 2003; Goodrich and Walker 2011), and ENSO and the Atlantic multidecadal oscillation (McCabe et al. 2004; McCabe et al. 2008). Few studies have focused on three or more interacting oscillations in atmospheric pressure patterns and their effect on regional precipitation in the United States. Understanding the interactions of these patterns could provide a more realistic model for seasonal precipitation projections.

In this study, we focus on five indices of large-scale climate variations that influence hydroclimatic conditions in North America: the Southern Oscillation index (SOI, the atmospheric component of ENSO), NAO, the East Atlantic pattern (EA), PNA, and the West Pacific pattern (WP). Fluctuations in the pressure centers that define these climate modes are an important influence on hydroclimatic variability in the United States through their effects on the intensification or deflection of moisture flow into different regions (Shinker et al. 2006). ENSO, a coupled system between the ocean and theatmosphere, is measured by fluctuations in ocean temperature and air pressure. ENSO has multiple effects on U.S. climate, including strengthening the subtropical jet, which brings energy and moisture from the Pacific Ocean into the western United States (Barnston et al. 1999). In an El Niño (SOI-) year, the Southwest,
Southeast, and Great Plains in the United States tend to be wet and the Pacific Northwest tends to be dry (Cole et al. 2002; Redmond and Koch 1991). La Niña (SOI+) conditions have been most strongly linked with dry conditions in the southwestern United States and more variable dry and wet conditions in the Great Plains and Pacific Northwest, respectively (Cole et al. 2002; Wise 2010). Recent work has emphasized the nonlinearity in the North American response to El Niño and La Niña conditions (Zhang et al. 2014).

NAO is based on a north-south dipole of air pressure anomalies between the Icelandic low and the Azores high (Barnston and Livezey 1987; Osborn 2011). This pattern is associated with changes in the Atlantic Ocean storm-track location and the intensity of the westerlies (Hurrell 1995). Although often linked to temperature impacts over North America rather than precipitation changes (e.g., Seager et al. 2010; Osborn 2011), variations in the strength and location of NAO "centers of action" can have an impact on low-level moisture transport and U.S. precipitation (Coleman and Budikova 2013). The negative phase of NAO has been associated with intrusion of Arctic air into the midlatitudes (Osborn 2011) and decreased streamflow in the northeastern United States, whereas the positive phase has been linked to high hydroclimatic variability in the eastern United States (Coleman and Budikova 2013).

The PNA pattern, one of the most prominent patterns of atmospheric variability in the Northern Hemisphere, indicates whether circulation across the United States is zonal or meridional (Ewen et al. 2008; Wallace and Gutzler 1981). In the positive phase, this pattern exhibits an enhanced Pacific Ocean jet and meridional flow, whereas the negative phase indicates zonal flow across North America (Henderson and Robinson 1994). These patterns lead to a dry western United States and a wet southeastern United States during the positive phase and generally wetter conditions across the United States during the negative PNA phase (Leathers et al. 1991). Although PNA has been shown to have a stronger relationship with temperature than with precipitation (Leathers et al. 1991), it also has a significant relationship with precipitation in many parts of the United States, especially in the Ohio River Valley (Coleman and Rogers 2003), along the Gulf Coast (Coleman and Rogers 2007), in the Southeast (Henderson and Robinson 1994; Katz et al. 2003), and in the West (Mock 1996).

Like NAO, EA and WP are both north-south dipoles of pressure anomalies. These anomalies are centered over the North Atlantic in the case of EA (southeast of the anomaly centers used to define NAO; Barnston and 
Livezey 1987), and the dipole centers are located over the Kamchatka Peninsula and southeastern Asia/ western North Pacific in the case of WP (Barnston and Livezey 1987). Positive EA is associated with strong ridging over Iceland and a northward displacement of the Azores high, whereas the negative phase is associated with more zonal flow and cold, polar air over eastern North America (Davis and Benkovic 1994). Changes in EA influence the position of the North Atlantic storm track and jet stream (Seierstad et al. 2007). Although most often included in studies of European climate, it has been suggested that EA and NAO may work in tandem to affect the latitude and speed of the jet stream (Woollings et al. 2010) and that a full understanding of NAO requires knowledge of EA (Moore et al. 2013). Shifts in WP, one of the primary modes of North Pacific low-frequency variability, are linked to changes in the placement and intensity of the AsiaPacific jet and are significantly correlated with temperature and precipitation in North America (Lau 1988; Linkin and Nigam 2008). The high subtropical pressurelow Kamchatka pressure phase of WP has been linked to wet conditions in California and mild winters in the Great Lakes region of the United States (Cayan et al. 1998; Rodionov and Assel 2000), whereas the low subtropical pressure-high Kamchatka pressure phase of WP is associated with wet conditions in the centralnorthern Rockies (Cayan et al. 1998).

The objective of this study is to determine the consistency of cool-season (October-March) precipitation impact patterns through varying phases of ENSO and NAO across the United States and how these impact patterns change when other Northern Hemisphere teleconnections are incorporated. While many teleconnection patterns reflect changes in both atmospheric and oceanic conditions, here we focus on teleconnections defined by atmospheric pressure anomalies, emphasizing the connections between altered atmospheric flow patterns and terrestrial precipitation. On the basis of the high degree of variability in spatial precipitation patterns that result from the interactions of these Northern Hemisphere teleconnection influences, we suggest that the inclusion of multiple climate modes may improve medium- and long-range precipitation forecasts.

\section{Data and methods}

This study focuses on five teleconnection patterns, each based on atmospheric pressure anomalies, which were chosen because of their climatic influences (described in the previous section): SOI, NAO, PNA, EA, and WP. Although several measures of the atmospheric and oceanic components of ENSO are available (Niño3.4, multivariate ENSO index, etc.), here we focus on the atmospheric component, SOI, which is based on air pressure differences between Tahiti and Darwin, Australia (Ropelewski and Jones 1987). SOI is frequently used for studies of cool-season precipitation in North America because of its strength as an ENSO indicator and its strong relationship with North American climate and streamflow over multimonth time periods (e.g., Redmond and Koch 1991; Cayan et al. 1999; Cook et al. 2014). NAO is closely associated with the Arctic Oscillation (AO), which has recently been linked to unusual winter conditions in North America (Cohen et al. 2010). Past research has indicated that the NAO-AO relationship is so close that the two can be used interchangeably (Holland 2003; Lapp et al. 2012) and that AO may not meet the traditional meteorological definition of a teleconnection pattern (Deser 2000; Ambaum et al. 2001; Itoh 2008). Because NAO and AO show a very high correlation in our dataset [similar to the monthly correlation of 0.95 reported by Deser (2000)], we omit AO in favor of NAO in these analyses.

Monthly values of each index, standardized to its 1981-2010 values, were obtained from the CPC (http:// cpc.ncep.noaa.gov). We conducted analyses on the coolseason months (October-March) from 1951 to 2011, for a total of 360 months. We chose to study the cool season because of the known links between these climate indices and cool-season moisture and because of the importance of cool-season precipitation for water supply and other sectors in the United States. The month of greatest importance for cool-season precipitation varies dramatically from place to place across the United States. The "shoulder" months of the cool season are particularly important for regions that rely on snowpack for their annual water supply, such as the western United States, and may become increasingly important through seasonality shifts in a warming climate. We extend our analyses beyond the traditionally defined December-February "winter" months and through the cool-season half year to capture this regional variability as well as to capture the state of the atmosphere over the whole season and reduce high-frequency fluctuations (Mills and Walsh 2013). Index data were divided into phases using cutoff values of \pm 0.5 , and index values between -0.5 and 0.5 were classified as neutral. This resulted in a range of 28-50 (average 39) months in each SOI/NAO phase combination (Table 1) and 3-29 (average 14) months when an additional teleconnection pattern was included (Table 2).

We used monthly precipitation data from the ParameterElevation Regressions on Independent Slopes Model (PRISM) dataset (http://www.prism.oregonstate.edu). 
TABLE 1. Number of months in each cool-season SOI/NAO phase combination.

\begin{tabular}{lcc}
\hline & $\mathrm{NAO}+$ & $\mathrm{NAO}-$ \\
\hline SOI+ & 32 & 50 \\
SOI- & 28 & 45 \\
\hline
\end{tabular}

The PRISM gridded dataset results from the interpolation of meteorological station data that have been prescreened for climatological studies and incorporate spatial information accounting for elevation, slope, rain shadows, temperature inversions, and coastal effects (Kangas and Brown 2007; Daly et al. 2008; Di Luzio et al. 2008). We converted the monthly PRISM values to 1 -month standardized precipitation index (SPI; McKee et al. 1993) values. For each month and grid cell, a gamma distribution function was fit to theobserved precipitation distribution, from which we obtained the cumulative probability for each precipitation observation, adjusted for the probability of observing zero precipitation during that month, and estimated SPI as the inverse normal of the gamma-fitted probability distribution (McKee et al. 1993; Wu et al. 2007). We then correlated the SPI values with the individual indices to determine the strength of the connection between the index and the spatial precipitation impact pattern. These spatial patterns allow us to visualize the regions of the United States that are most likely to be wetter or drier than average under positive or negative teleconnection conditions. Although the PRISM dataset offers fine spatial resolution, extensive quality control of station data prior to interpolation, and expert review of climate fields (Daly et al. 2008), the interpolation process may induce spatial smoothing of the precipitation fields (Meko et al. 2011). The interpolation of station data may therefore result in the inflation (or deflation) of statistically significant anomaly regions, especially in areas with low station density, and we therefore suggest that the boundaries of significant anomaly patterns should be regarded as approximations.

To study the impact of teleconnection interactions on cool-season precipitation, we first considered subsets that included only SOI and NAO (Table 1) because of their importance for seasonal climate forecasts. We then formed further subsets that incorporate a third teleconnection pattern (EA, PNA, or WP; Table 2). Once the months were separated into subsets, the average PRISM SPI values for each subset were calculated. The significance level of the SPI values in each set was determined through a random permutation resampling method, whereby sets of precipitation anomaly values corresponding to the number of years in the phase
TABLE 2. Number of months in each cool-season teleconnection-phase subset.

\begin{tabular}{lcccc}
\hline \hline & $\begin{array}{c}\text { SOI+l } \\
\text { NAO+ }\end{array}$ & $\begin{array}{c}\text { SOI+l } \\
\text { NAO- }\end{array}$ & $\begin{array}{r}\text { SOI-/ } \\
\text { NAO+ }\end{array}$ & $\begin{array}{r}\text { SOI-l } \\
\text { NAO- }\end{array}$ \\
\hline EA+ & 6 & 14 & 12 & 20 \\
EA- & 14 & 21 & 10 & 17 \\
PNA + & 11 & 11 & 9 & 19 \\
PNA- & 12 & 29 & 8 & 9 \\
WP+ & 15 & 11 & 13 & 16 \\
WP- & 7 & 25 & 3 & 15 \\
\hline
\end{tabular}

combination were randomly sampled 1000 times from the set of all October-March periods and averaged together to calculate mean SPI. SPI values are considered to be significant at the $95 \%$ confidence level if their magnitude is above the 97.5th or below the 2.5 th percentile of the random permutations. To examine atmospheric circulation features associated with the teleconnection patterns, we obtained $500-\mathrm{hPa}$ geopotential height (GPH) data from the Twentieth Century Reanalysis Project (20CR2; Compo et al. 2011) and calculated standardized monthly anomaly values using

$$
Z=(X-\mu) / \sigma
$$

where $X$ is the individual month's total precipitation and $\mu$ and $\sigma$ are the mean total precipitation and the standard deviation, respectively, for that month over the entire time period. Composite maps were then created using the GPH anomalies in each of the phase subsets under study. We display GPH anomalies (overlaid by raw GPH measurements) to emphasize the anomalous centers of low and high pressure that are associated with the precipitation patterns.

\section{Results}

Correlations between monthly precipitation values and teleconnection indices demonstrate the spatial impact patterns of the individual teleconnections across the United States (Fig. 1). These correlation maps show the relationship of atmospheric anomalies in each climate pattern with regions of high or low precipitation; strength of correlations may be muted by the use of the extended October-March cool season rather than the traditionally defined December-February winter season. Regions with notably strong correlations include the strongly negative correlations between SOI and the southern United States, the negative correlation of precipitation in the Ohio River Valley with PNA, a positive correlation around the Great Lakes with NAO, the connection of EA with the central and southeastern United States, and WP's impact in the Pacific Northwest (Fig. 1). 

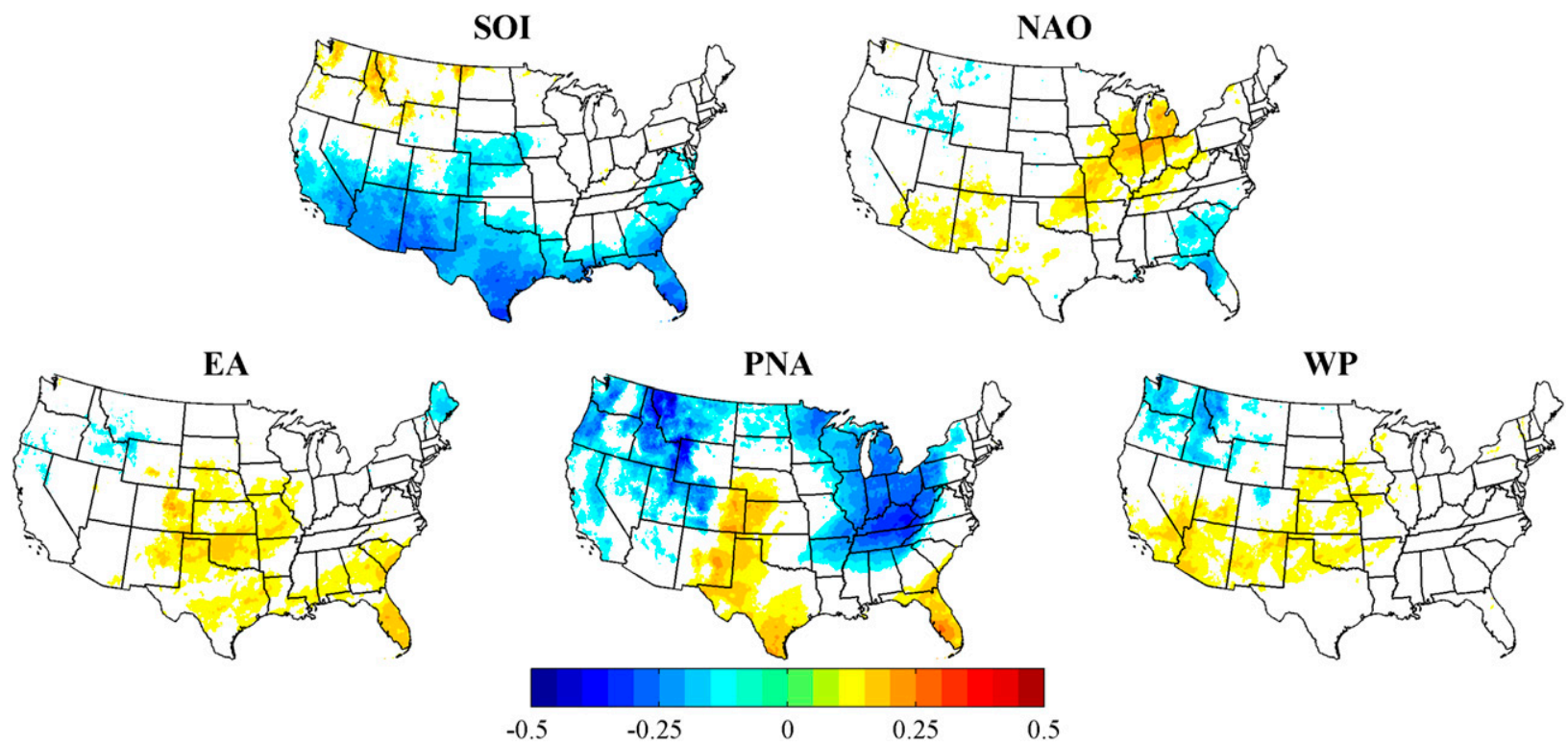

FIG. 1. Correlations between average cool-season SPI and teleconnection indices. Only correlations significant at or above a $95 \%$ confidence level are shown.

Phase-combination precipitation-impact patterns of ENSO and NAO (Fig. 2) confirm that the southern United States tends to be wetter in El Niño winters (SOI-) than in La Niña winters (SOI+), in agreement with previous research (e.g., Redmond and Koch 1991;
Wise 2010). SOI and NAO appear to have the largest impact on precipitation during $\mathrm{SOI}+\mathrm{NAO}-$ and $\mathrm{SOI}-/ \mathrm{NAO}+$ phase combinations, but there are important regional exceptions (Fig. 2). The regions of most strongly anomalous wet conditions during
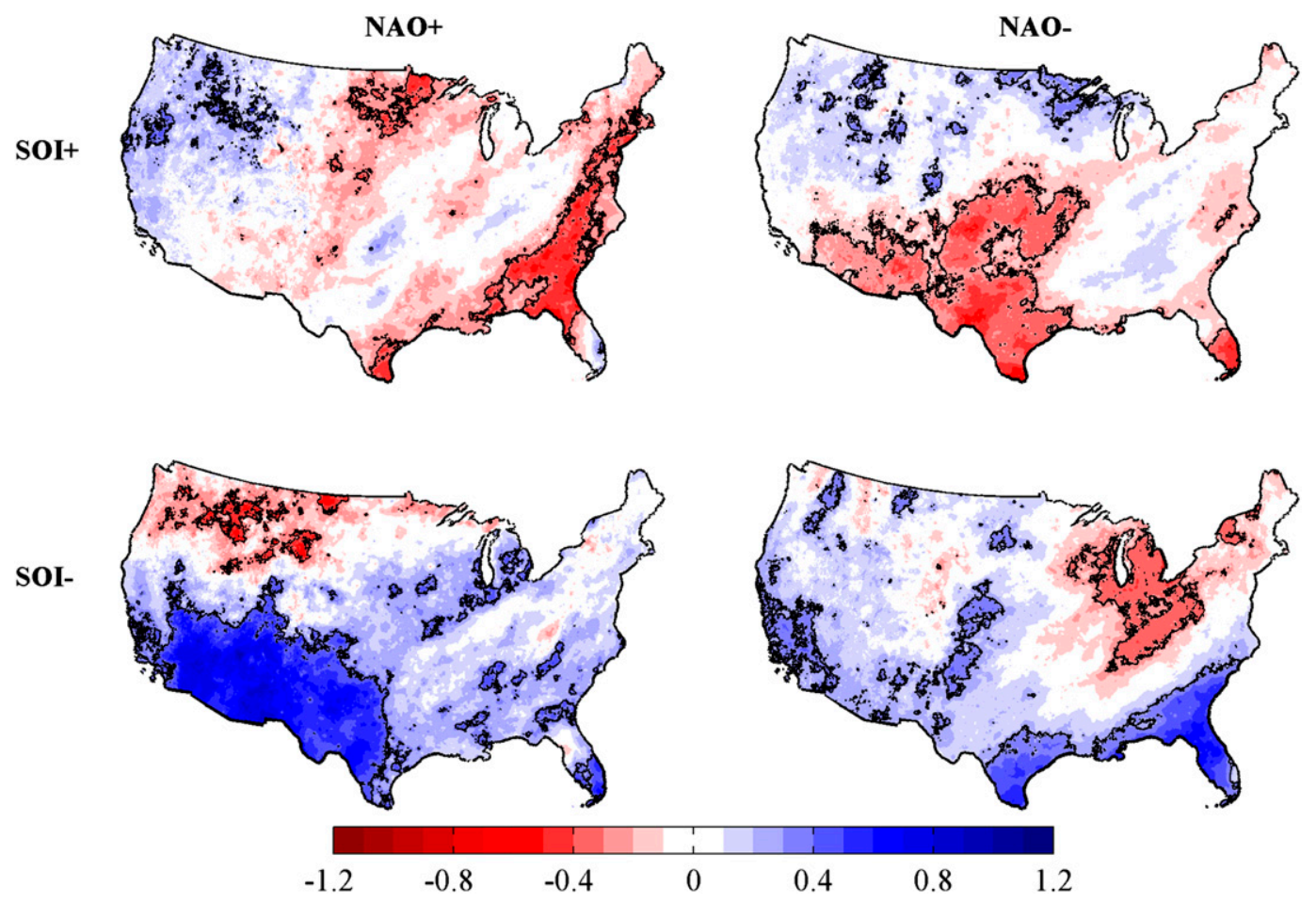

FIG. 2. Average cool-season SPI for SOI/NAO phase combinations. Areas significant at or above the $95 \%$ confidence level are contoured. 

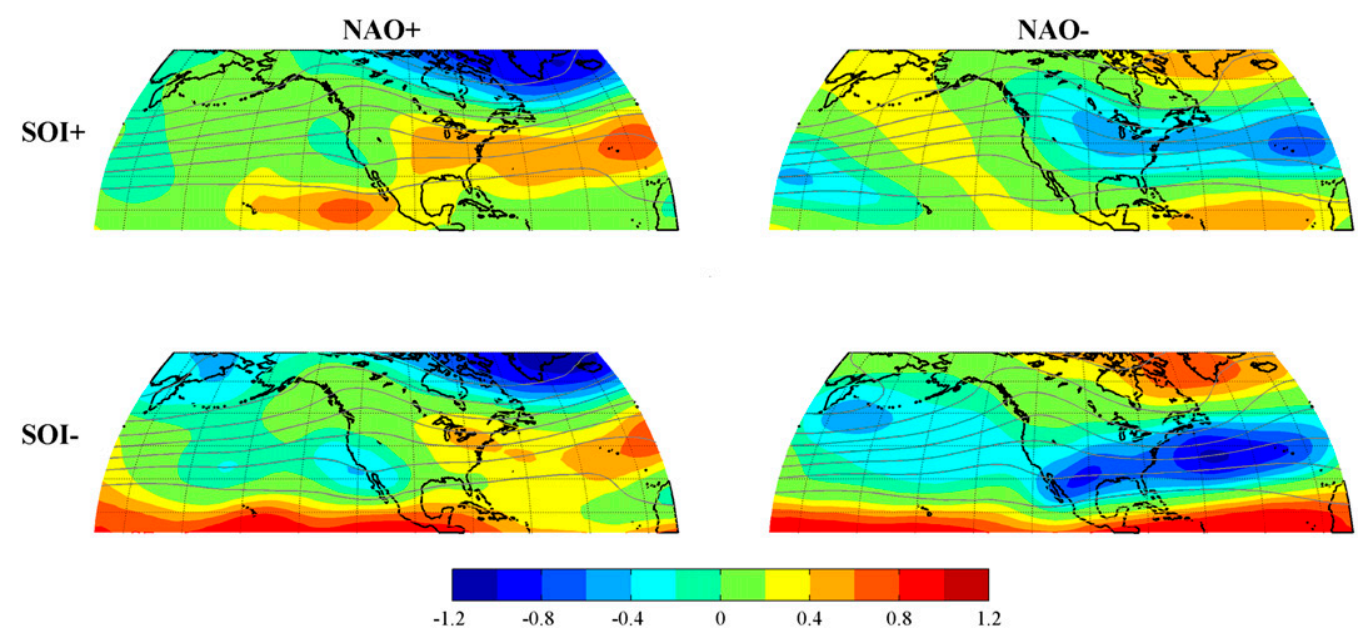

FIG. 3. Composite maps of cool-season standardized 500-hPa GPH anomalies for SOI/NAO phase combinations (shown with shading). Overlaid contours indicate raw GPH (m); the southernmost contour is $5800 \mathrm{~m}$, and the contour interval is $100 \mathrm{~m}$.

SOI- shift eastward from the Southwest $(\mathrm{NAO}+)$ to Florida and the Gulf Coast under NAO- conditions, and the strongest dry anomalies in the Great Lakes region occur under the SOI-/NAO- combination. The SOI-/NAO- phase combination is also associated with wet conditions over much of California. The regions of anomalous dry conditions during $\mathrm{SOI}+$ shift eastward from the Southwest (NAO-) to the eastern United States under NAO+ conditions. With just a few regional exceptions (most notably the strong "La Niña-like" Pacific Northwest-desert Southwest dipole pattern in the SOI+/neutral-NAO phase), neutral phases tend to have few regions with significant anomalies (not shown). Therefore, we consider only the positive and negative phases during the remaining portion of our study.

The SOI/NAO precipitation patterns shown in Fig. 2 have clear connections to synoptic pressure patterns (Fig. 3). The strengthened Icelandic low and Azores high during NAO+ (Fig. 3, first column) and opposite conditions during NAO - (Fig. 3, second column) can be seen in both rows (SOI+ and SOI-), but with important differences depending on SOI phase. During SOI + / $\mathrm{NAO}+$, high pressure anomalies extend into the eastern United States, with associated dry conditions. During $\mathrm{SOI}-/ \mathrm{NAO}+$, neutral conditions prevail over the East while low pressure (and wet conditions) are dominant in the Southwest. A strong low pressure trough extends across the southern United States in the NAO-/SOImonths. The links between dry conditions in the central United States and GPH patterns seen in the SOI+/ $\mathrm{NAO}-$ phase are less clear from Fig. 3, but may be associated with a slight northward shift in the storm-track position under these conditions.
Examining the precipitation impact patterns of NAO and SOI after the incorporation of other important teleconnections-EA, PNA, and WP-helps to illuminate their interactions and associated changes in cool-season precipitation (Figs. 4 and 5). Combined SOI/NAO positive phases tend to show few regions of significant deviations in SPI (left two columns in Fig. 4). ENSO does appear to have the largest effect on the sign of the anomaly (more dry regions in Fig. 4 and more wet regions in Fig. 5), although each phase combination has a unique spatial precipitation pattern. For example, when all patterns are negative (Fig. 5, rightmost column), the Mid-Atlantic and Northeast may experience dry (EA-), wet (PNA-), or neutral (WP-) conditions. Even for regions of the country with similar responses, as seen in the central and southwestern U.S. wet conditions under SOI-/NAO+ (leftmost column in Fig. 5), the addition of a third teleconnection has an impact on the size of the affected region and the magnitude of the anomaly, possibly as a result of the storm-track response to atmospheric pressure changes. In the SOI-/NAO+ example, under EA+, much of the central United States is anomalously wet. During PNA +, only small areas are significantly wetter than average. During $\mathrm{WP}+$, the Midwest and Great Plains have expanded wet anomalies while the Pacific Northwest displays a stronger dry signal. The Pacific Northwest displays unexpected wet conditions during SOI- months combined with NAOand $\mathrm{WP}-$ phases (Fig. 5). Some of the phase combinations (particularly $\mathrm{SOI}-/ \mathrm{NAO}+/ \mathrm{WP}-$ ) occurred very few times over the study period (Table 2 ) and should be interpreted with caution.

When SOI was positive, the phase of EA appears to have influenced the observed precipitation patterns, 
SOI + /NAO+
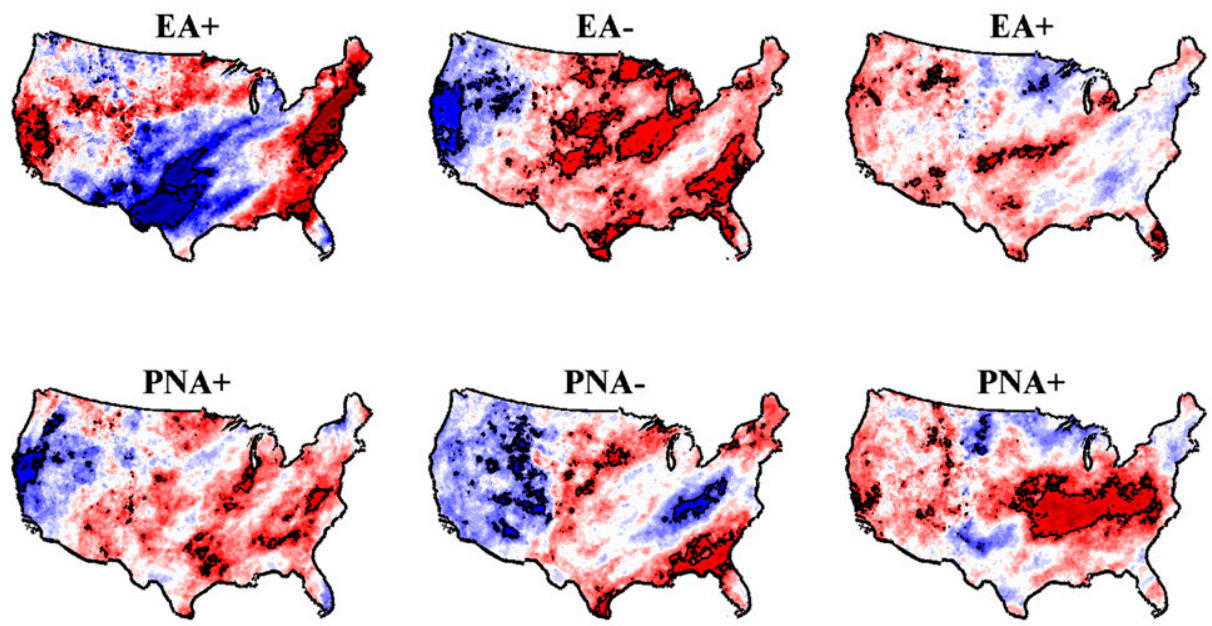

SOI+/NAO-
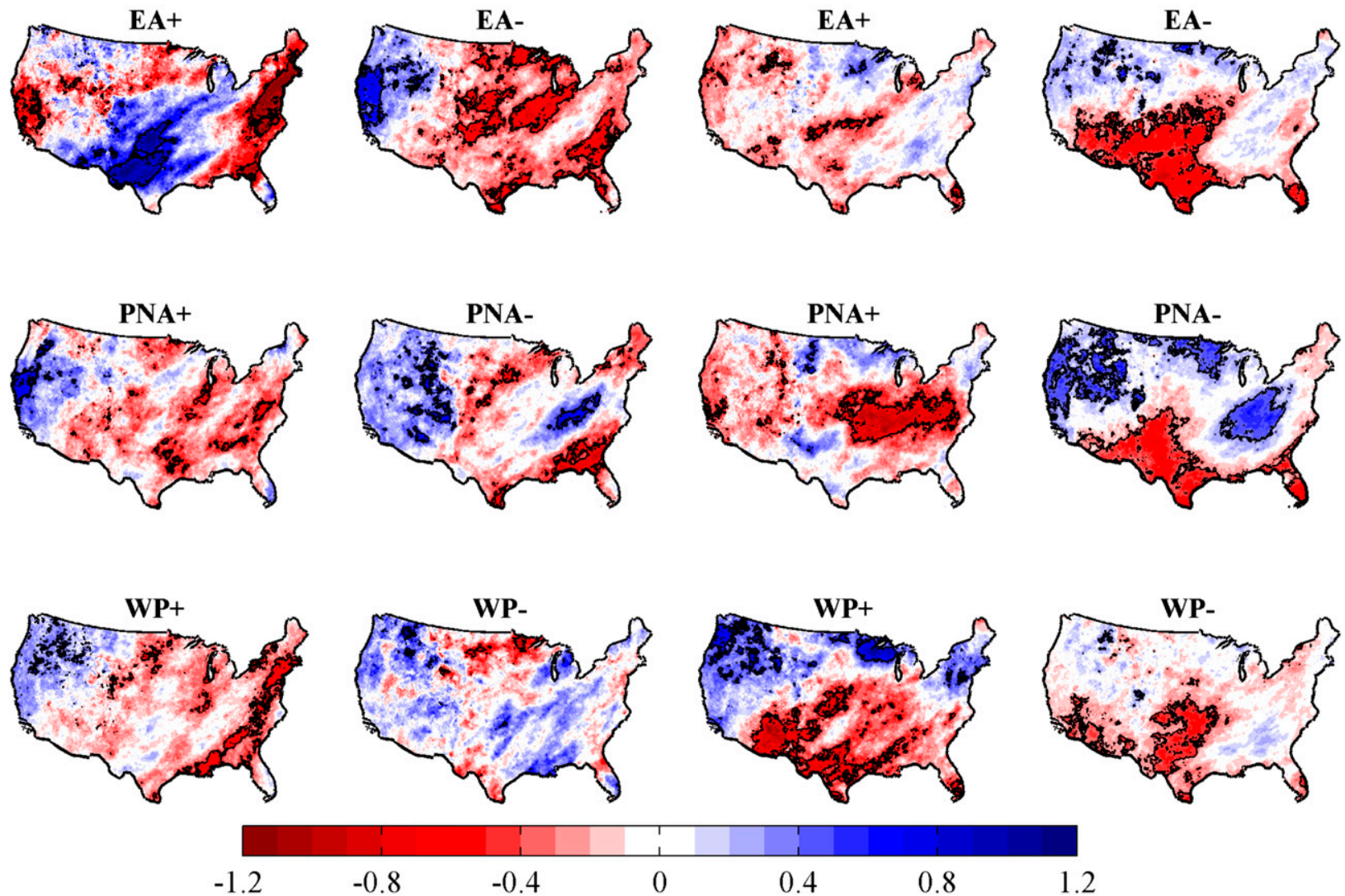

$-0.8$

$-0.4$

0

0.4

0.8

FIG. 4. Average cool-season SPI for (left two columns) SOI+/NAO+ and (right two columns) SOI+/NAO-. Rows incorporate a third teleconnection pattern (EA, PNA, and WP). Areas significant at or above the $95 \%$ confidence level are contoured.

with drier conditions in the east and west and wetter conditions in the central United States during the $\mathrm{NAO}+/ \mathrm{EA}+$ phase combination (relative to $\mathrm{NAO}+/$ $\mathrm{EA}-)$ and wetter conditions in the west and drier conditions in the central United States during the NAO-/ $\mathrm{EA}-$ phase combination (relative to $\mathrm{NAO}-/ \mathrm{EA}+$ ) (Fig. 4). During the SOI+/NAO+/EA+ phase combination GPH anomalies show high pressure ridges over the eastern half of the United States and off the West Coast, whereas during SOI+/NAO-/EA - a low pressure trough extends across British Columbia, Canada, and across the Great Lakes to the Atlantic Ocean (Fig. 6). In contrast, during SOI- the EA phase does not seem to greatly affect precipitation patterns, but the phase of WP is important for the Pacific Northwest (wetter conditions when WP-), and PNA phase changes the patterns in the Great Lakes region (Fig. 5). When SOI is negative, the negative WP phase is associated with a weakened Aleutian low and low pressure in the central North Pacific (Fig. 7).

The ridge over the western United States and trough over the eastern United States expected under PNA+ conditions appears in all phase combinations of SOI and $\mathrm{NAO}$ except for $\mathrm{SOI}+\mathrm{NAO}+$, when the high pressure ridge is over the central United States and there is no associated eastern trough (Figs. 6 and 7). Even when the $\mathrm{PNA}+$ ridge-trough pattern is observed, though, the centers of the high and low pressure areas shift, with associated shifts in precipitation on the ground. The traditional PNA - consists of low pressure over the western United States and high pressure anomalies in the East. This pattern is clear under $\mathrm{NAO}+$ conditions for both SOI phases (Figs. 6 and 7) but not during $\mathrm{NAO}-$, for which there is troughing over the West but no ridging over the East, regardless of SOI phase.

It is important to note that these composites over the 6-month cool season may mask important variability among the late-autumn, midwinter, and early-spring months. Compositing techniques can have the effect of obscuring differences between individual cases. The months that are most important for teleconnectionprecipitation impacts in the United States will vary by location and teleconnection, as well as between individual years. For instance, studies on PNA have 


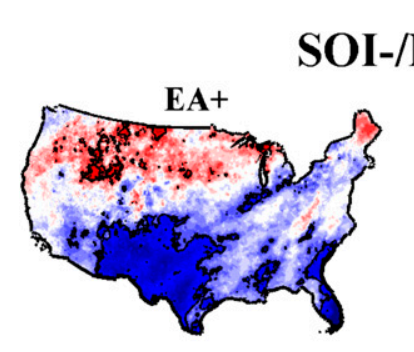

\section{NAO+}

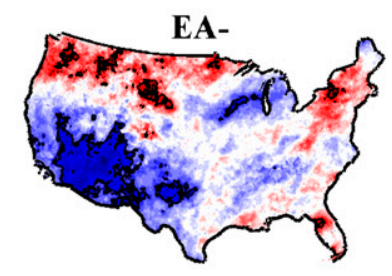

EA-

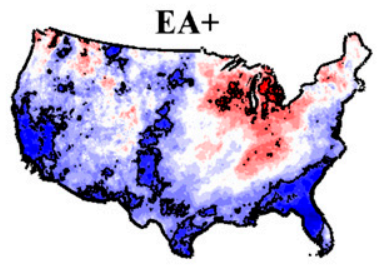

SOI-/NAO-
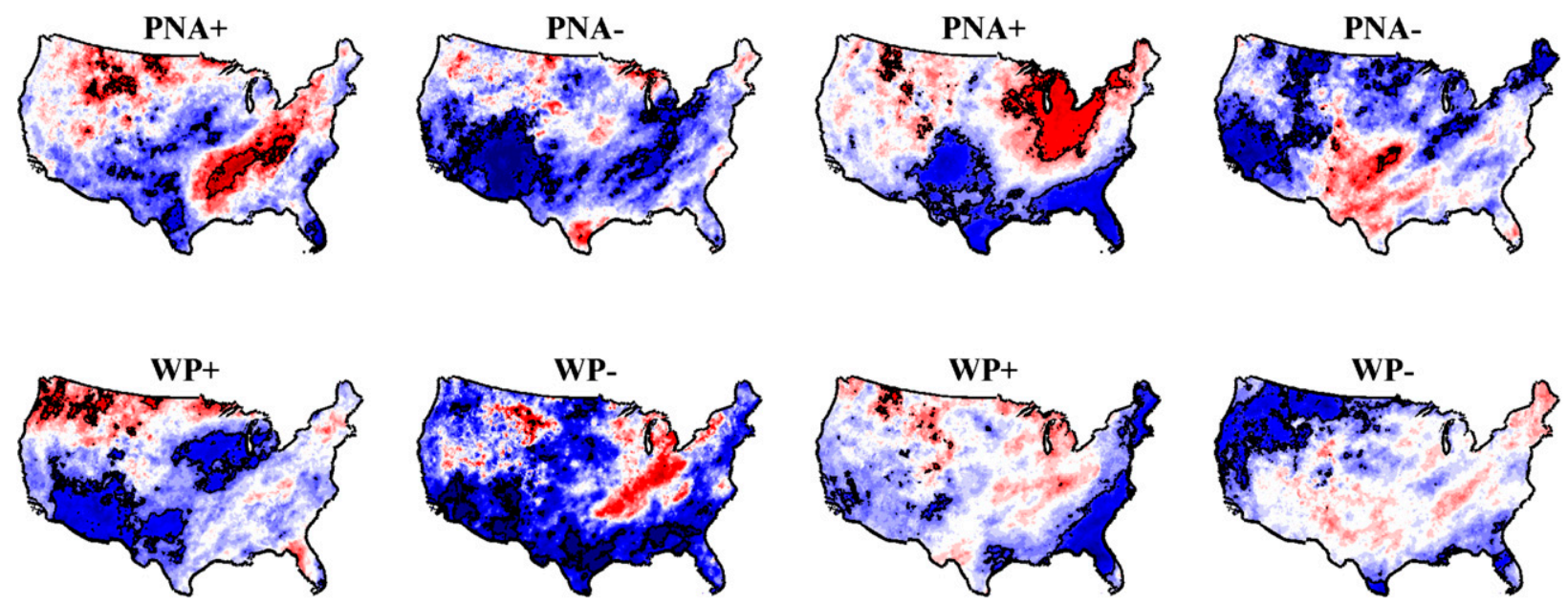

$-1.2$

$-0.8$

$-0.4$

0
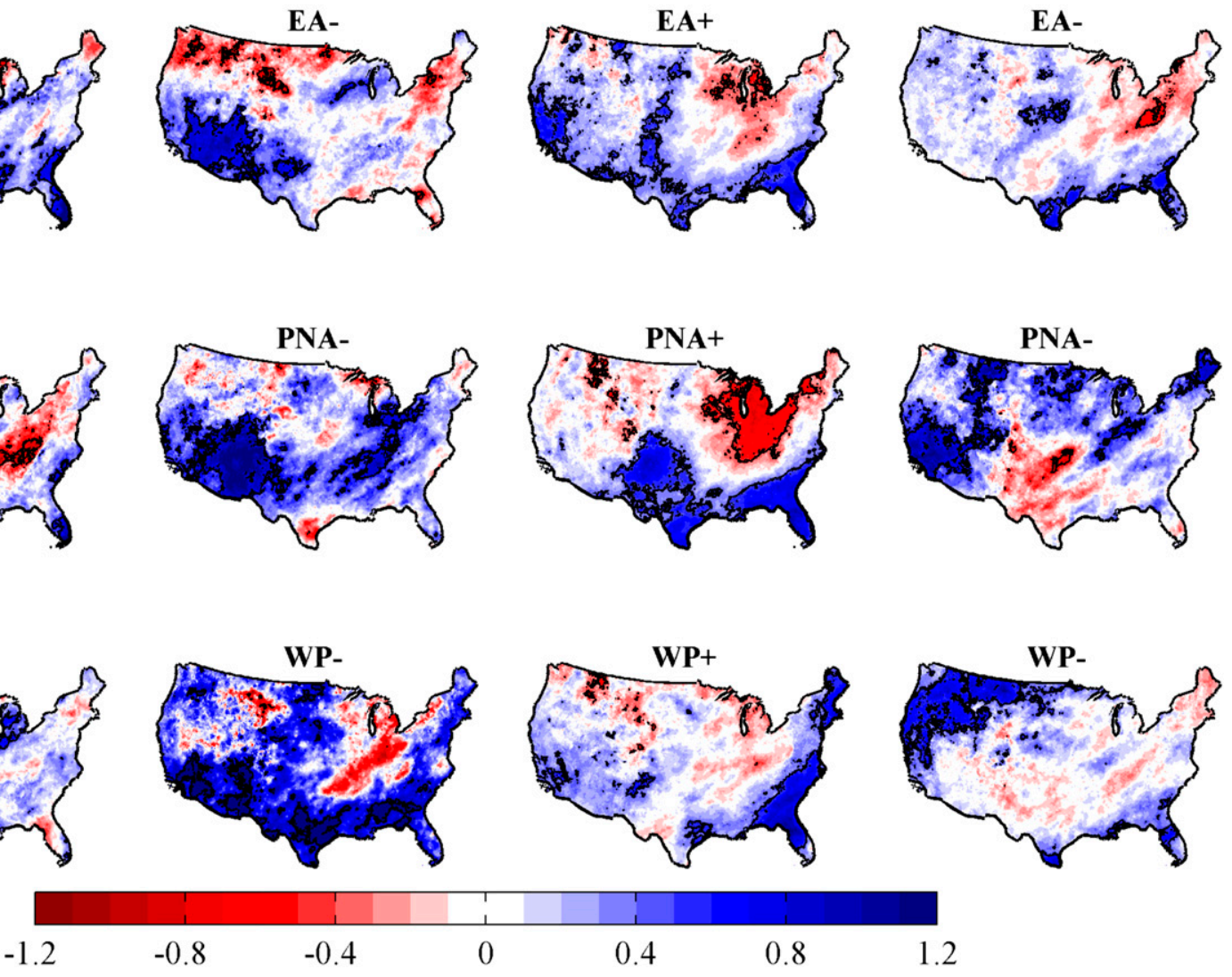

FIG. 5. As in Fig. 4, but for (left two columns) SOI-/NAO+ and (right two columns) SOI-/NAO-.

often only examined impacts over December-February (e.g., Wallace and Gutzler 1981; Katz et al. 2003), but research involving additional months has found PNA impacts on climate in multiple seasons (e.g., Leathers et al. 1991; Coleman and Rogers 2007) and has suggested that the month of strongest impact may vary depending on the particular climate parameter under study (Henderson and Robinson 1994). In addition, there are indications that the teleconnection seasonal associations may change in a warming climate (McAfee and Russell 2008). For comparison between the OctoberMarch cool-season results shown in Figs. 4-7 and the December-February core winter months, we repeated our analyses using December-February only; these results are presented in Table S1 and Figs. S1-S4 in the online supplemental material for this paper. The SPI and GPH patterns over December-February are very similar to their October-March counterparts in the SOI/NAO/PNA phase combinations, suggesting that the October-March composites are capturing winter patterns. It is also important to note the small sample sizes in these DecemberFebruary subsets: 18 of the 24 phase-combination subsets are composites of fewer than 10 individual months (see Table S1).

\section{Discussion and conclusions}

The complexity of the climate system is clear when interactions between climate modes are considered. All five teleconnections in our study, and others not included here, can occur simultaneously, with resulting variability in impact patterns. Medium- to long-range climate forecasts are frequently consulted by water managers (Wedgbrow et al. 2002; Werritty 2002), ecologists (Helmuth et al. 2006; Moen 2008), and others looking for predictive information (Hansen et al. 2006; Thomson et al. 2006). Although some atmospheric patterns receive more attention than others, knowledge of multiple teleconnections and their spatial impacts would be useful for improving the reliability of seasonal forecasts.

In this study, we show that a wide variety of precipitation conditions can occur when different phases of five prominent climate modes interact. Previous 


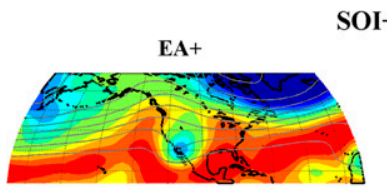

SOI+/NAO+
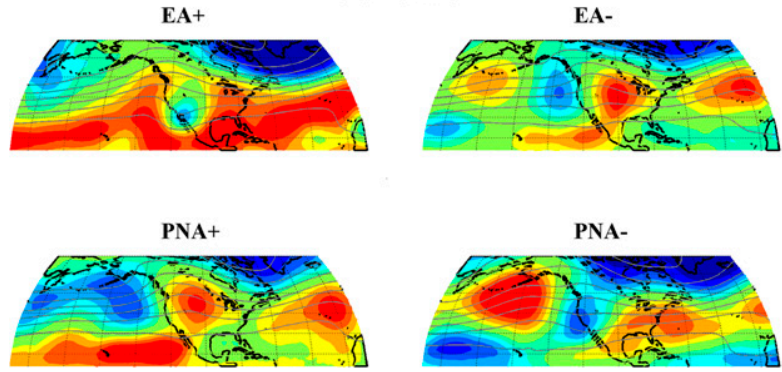

WP+

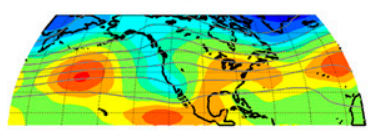

PNA-
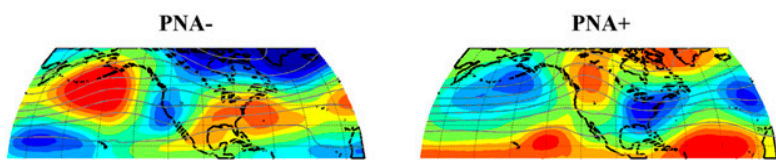

WP-

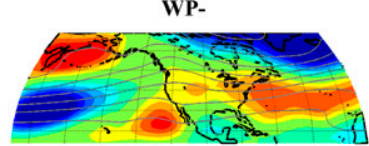

WP+

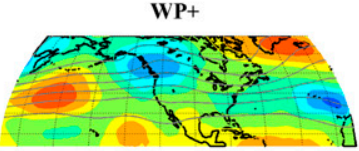

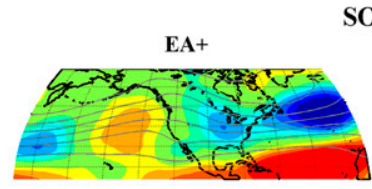

SOI+/NAO-
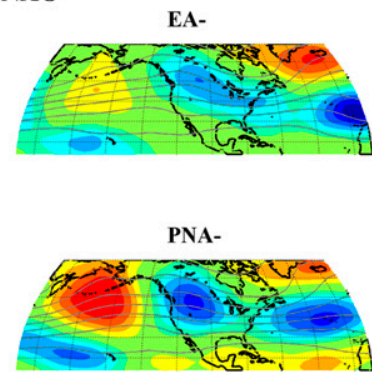

WP-

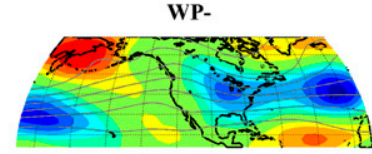

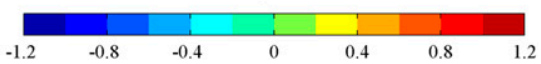

FIG. 6. Composite maps of cool-season standardized 500-hPa GPH anomalies (shown with shading): (left two columns) SOI+/NAO+ and (right two columns) SOI+/NAO - . Rows incorporate a third teleconnection pattern (EA, PNA, and WP). Overlaid contours indicate raw $\mathrm{GPH}(\mathrm{m})$; the southernmost contour is $5800 \mathrm{~m}$, and the contour interval is $100 \mathrm{~m}$.

research had suggested that EA and NAO may work together to influence atmospheric circulation and related climate patterns (Woollings et al. 2010; Moore et al. 2013). Our results show that the influence of EA is much stronger when SOI+ conditions also occur (Fig. 4). The West Pacific pattern has been similarly linked to changes in the Asian-Pacific jet and associated climate patterns in North America (Lau 1988; Linkin and Nigam 2008). It does appear to influence the North American climate, but primarily in the Pacific Northwest during SOI- conditions (Fig. 5). This is likely tied to the entrance region of the Pacific jet into the North
American continent. PNA exerts a strong influence on precipitation across North America regardless of SOI or NAO phase (Figs. 4 and 5). Although the ridge-trough pattern expected with strong PNA anomalies is present in most SOI/NAO phase combinations, the placement of the ridge and trough axes shifts (Figs. 6 and 7), with resulting implications for precipitation in the United States.

The months of strongest teleconnection influence, as well as the months that are most critical for precipitation impacts, vary over space and time. In this study, we focused primarily on the longer "cool season" (October-March)

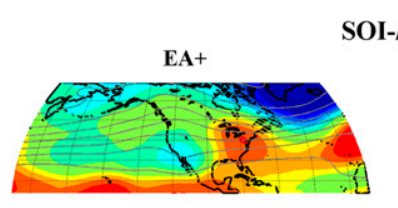

PNA+

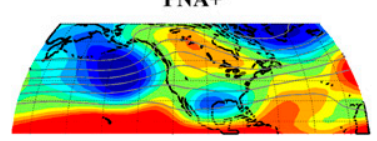

WP+

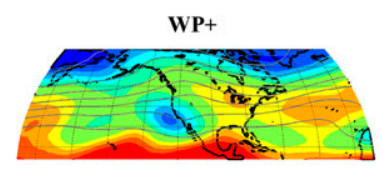

EA-

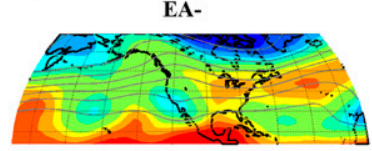

PNA-

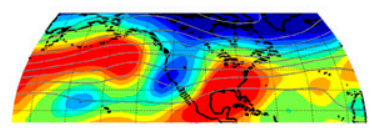

WP-

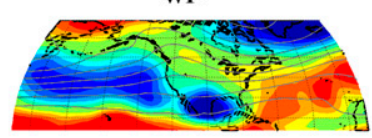

SOI-/NAO-

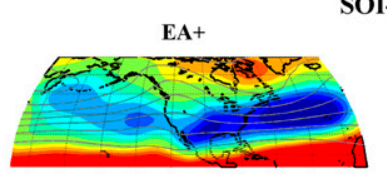

PNA+

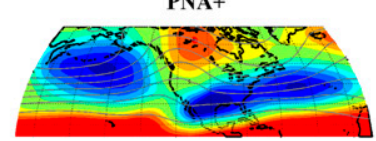

WP+

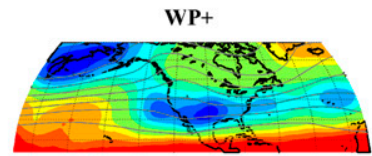

EA-

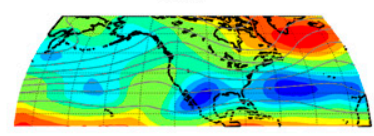

PNA-

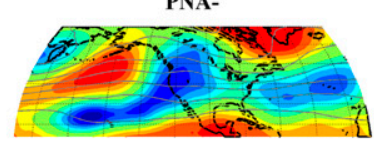

WP-

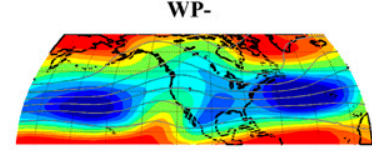

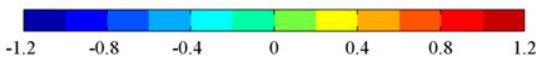

FIG. 7. As in Fig. 6, but for (left two columns) SOI-/NAO+ and (right two columns) SOI-/NAO- 
rather than winter (December-February) to capture the full cool-season range across the United States and to examine these teleconnection-precipitation associations as they relate to synoptic-scale pressure patterns. A limitation of this approach is that it may mask nuances between months and among regions. The teleconnections examined here frequently display different patterns in the early winter versus in the late winter, and the months in which these teleconnections are most important for seasonal planning purposes will also vary by region. In addition, there may be more interannual variability in the shoulder months as compared with December-February in both precipitation and GPH. The October-March period also might not extend far enough to capture all aspects of the impacts in some regions; for example, Coleman and Budikova (2013) identified NAO hydroclimatic impacts in the northeastern United States that extend across the winter, spring, and summer seasons. Further research will be needed to build on these U.S.-wide results by examining this variability at the regional scale.

Overall, these results demonstrate that basing a seasonal forecast solely on ENSO would not capture the variability that occurs through the interactions of multiple climatic patterns across the United States. Nonlinearities in these oscillations should also be considered. For example, it has been shown that an El Niño of a certain magnitude is unlikely to have precisely the opposite effect of a La Niña of the same magnitude in North America (Hoerling et al. 1997) and that negative phases of NAO may more strongly affect some regions in the United States (Coleman and Budikova 2013). The asymmetries observed in the teleconnection impacts on North American climate have been linked to asymmetry in the midtropospheric circulation (Zhang et al. 2014). The results of this study (see Figs. 2, 4, and 5) confirm the prevalence of nonlinear impacts in the United States.

Many regions of the United States lack a consistent precipitation response to teleconnection indices, limiting the potential for seasonal forecasting. In the midwestern United States, for instance, our work shows that when $\mathrm{SOI}+$ combines with the NAO- phase regional conditions could range from anomalously wet when PNA is negative, neutral when WP is negative, or dry when PNA is positive (Fig. 4). During SOI-/NAOphase combinations, this region can be anomalously wet during PNA - conditions, neutral when WP is negative, and dry when PNA+ or EA- occur (Fig. 5). Therefore, forecasts that are based on ENSO or NAO may not be effective tools for the Midwest, and multiple teleconnections may need to be incorporated to improve seasonal projections.
It is likely that many users of climate information are most familiar with ENSO because of its global importance and its frequent mention in local newscasts and other media outlets. As shown here, ENSO does not have the greatest impact on all regions of the United States. Planners and managers in the Northeast and the Great Lakes-regions where ENSO does not typically have a large effect-may be better served by information concerning other teleconnections, such as NAO and PNA. The inclusion of more climate information in seasonal forecasts would not only improve the reliability of the projections but could also make the forecasts more applicable to a wider geographic range. For stakeholders who rely on climate information, stronger seasonal forecasts would aid the decisionmaking process.

We anticipate that seasonal predictions of precipitation could be improved through the incorporation of multiple climate modes in a regional forecast. A focus on regionally important indices by weather forecasters could also serve as an educational tool concerning the complexity of the climate system. The teleconnection combinations and their respective precipitation-anomaly patterns may provide extra guidance for regional water planners to use when forecasting seasonal precipitation and may act as a guide for additional analysis by a regional forecaster. Although seasonal projections cannot capture all of the intricacies of atmospheric conditions and climate systems, inclusion of regionally important teleconnection patterns would be a step forward in producing more accurate forecasts.

Acknowledgments. This research was supported by the NSF P2C2 program under Grant AGS-1102757.

\section{REFERENCES}

Agrawala, S., K. Broad, and D. H. Guston, 2001: Integrating climate forecasts and societal decision making: Challenges to an emergent boundary organization. Sci. Technol. Human Values, 26, 454-477, doi:10.1177/016224390102600404.

Ambaum, M., B. Hoskins, and D. Stephenson, 2001: Arctic Oscillation or North Atlantic Oscillation? J. Climate, 14, 3495-3507, doi:10.1175/1520-0442(2001)014<3495: AOONAO $>2.0 . \mathrm{CO} ; 2$.

Barnston, A. G., and R. E. Livezey, 1987: Classification, seasonality, and persistence of low-frequency atmospheric circulation patterns. Mon. Wea. Rev., 115, 1083-1126, doi:10.1175/ 1520-0493(1987)115<1083:CSAPOL > 2.0.CO;2.

- A. Leetmaa, V. E. Kousky, R. E. Livezey, E. O’Lenic, H. Van den Dool, A. J. Wagner, and D. A. Unger, 1999: NCEP forecasts of the El Niño of 1997-98 and its U.S. impacts. Bull. Amer. Meteor. Soc., 80, 1829-1852, doi:10.1175/ 1520-0477(1999)080<1829:NFOTEN>2.0.CO;2.

Cayan, D. R., M. D. Dettinger, H. F. Diaz, and N. E. Graham, 1998: Decadal variability of precipitation over western North 
America. J. Climate, 11, 3148-3166, doi:10.1175/ 1520-0442(1998)011<3148:DVOPOW >2.0.CO;2.

K. T. Redmond, and L. G. Riddle, 1999: ENSO and hydrologic extremes in the western United States. J. Climate, 12, 2881-2893, doi:10.1175/1520-0442(1999)012<2881: EAHEIT $>2.0 . \mathrm{CO} ; 2$.

Cherry, J., H. Cullen, M. Visbeck, A. Small, and C. Uvo, 2005: Impacts of the North Atlantic Oscillation on Scandinavian hydropower production and energy markets. Water Resour. Manage., 19, 673-691, doi:10.1007/s11269-005-3279-z.

Cohen, J., J. Foster, M. Barlow, K. Saito, and J. Jones, 2010: Winter 2009-2010: A case study of an extreme Arctic Oscillation event. Geophys. Res. Lett., 37, L17707, doi:10.1029/2010GL044256.

Cole, J. E., J. T. Overpeck, and E. R. Cook, 2002: Multiyear La Niña events and persistent drought in the contiguous United States. Geophys. Res. Lett., 29, doi:10.1029/2001GL013561.

Coleman, J. S. M., and J. C. Rogers, 2003: Ohio River Valley winter moisture conditions associated with the Pacific-North American teleconnection pattern. J. Climate, 16, 969-981, doi:10.1175/ 1520-0442(2003)016<0969:ORVWMC $>2.0 . C O ; 2$.

— and - 2007: A synoptic climatology of the central United States and associations with Pacific teleconnection pattern frequency. J. Climate, 20,3485-3497, doi:10.1175/JCLI4201.1.

_ and D. Budikova, 2013: Eastern U.S. summer streamflow during extreme phases of the North Atlantic Oscillation. J. Geophys. Res. Atmos., 118, 4181-4193, doi:10.1002/jgrd.50326.

Compo, G. P., and Coauthors, 2011: The Twentieth Century Reanalysis Project. Quart. J. Roy. Meteor. Soc., 137, 1-28, doi:10.1002/qj.776.

Cook, B. I., J. E. Smerdon, R. Seager, and E. R. Cook, 2014: Pancontinental droughts in North America over the last millennium. J. Climate, 27, 383-397, doi:10.1175/JCLI-D-13-00100.1.

Dai, A., and T. M. L. Wigley, 2000: Global patterns of ENSOinduced precipitation. Geophys. Res. Lett., 27, 1283-1286, doi:10.1029/1999GL011140.

Daly, C., M. Halbleib, J. I. Smith, W. P. Gibson, M. K. Doggett, G. H. Taylor, J. Curtis, and P. Pasteris, 2008: Physiographically sensitive mapping of climatological temperature and precipitation across the conterminous United States. Int. J. Climatol., 28, 2031-2064, doi:10.1002/joc.1688.

Davis, R., and S. Benkovic, 1994: Spatial and temporal variations of the January circumpolar vortex over the Northern Hemisphere. Int. J. Climatol., 14, 415-428, doi:10.1002/joc.3370140406.

Deser, C., 2000: On the teleconnectivity of the "Arctic Oscillation." Geophys. Res. Lett., 27, 779-782, doi:10.1029/ 1999GL010945.

Di Luzio, M., G. L. Johnson, C. Daly, J. K. Eischeid, and J. G. Arnold, 2008: Constructing retrospective gridded daily precipitation and temperature datasets for the conterminous United States. J. Appl. Meteor. Climatol., 47, 475-497, doi:10.1175/2007JAMC1356.1.

Ewen, T., S. Broennimann, and J. Annis, 2008: An extended Pacific-North American index from upper-air historical data back to 1922. J. Climate, 21, 1295-1308, doi:10.1175/ 2007JCLI1951.1.

Fereday, D. R., A. Maidens, A. Arribas, A. A. Scaife, and J. R. Knight, 2012: Seasonal forecasts of Northern Hemisphere winter 2009/10. Environ. Res. Lett., 7, 034031, doi:10.1088/ 1748-9326/7/3/034031.

Goodrich, G. B., and J. M. Walker, 2011: The influence of the PDO on winter precipitation during high- and low-index ENSO conditions in the eastern United States. Phys. Geogr., 32, 295312, doi:10.2747/0272-3646.32.4.295.
Gutzler, D. S., D. M. Kann, and C. Thornbrugh, 2002: Modulation of ENSO-based long-lead outlooks of southwestern U.S. winter precipitation by the Pacific decadal oscillation. Wea. Forecasting, 17, 1163-1172, doi:10.1175/1520-0434(2002)017<1163: MOEBLL $>2.0 . C O ; 2$.

Hansen, J. W., A. Challinor, A. Ines, T. Wheeler, and V. Moron, 2006: Translating climate forecasts into agricultural terms: Advances and challenges. Climate Res., 33, 27-41, doi:10.3354/ cr033027.

Helmuth, B., N. Mieszkowska, P. Moore, and S. J. Hawkins, 2006: Living on the edge of two changing worlds: Forecasting the responses of rocky intertidal ecosystems to climate change. Annu. Rev. Ecol. Evol. Syst., 37, 373-404, doi:10.1146/ annurev.ecolsys.37.091305.110149.

Henderson, K. G., and P. J. Robinson, 1994: Relationships between the Pacific/North American teleconnection patterns and precipitation events in the south-eastern USA. Int. J. Climatol., 14, 307-323, doi:10.1002/joc.3370140305.

Hidalgo, H. G., and J. A. Dracup, 2003: ENSO and PDO effects on hydroclimatic variations of the Upper Colorado River basin. J. Hydrometeor., 4, 5-23, doi:10.1175/1525-7541(2003)004<0005: $\mathrm{EAPEOH}>2.0 . \mathrm{CO} ; 2$.

Hoerling, M. P., A. Kumar, and M. Zhong, 1997: El Niño, La Niña, and the nonlinearity of their teleconnections. J. Climate, 10, 1769-1786, doi:10.1175/1520-0442(1997)010<1769: ENOLNA $>2.0 . \mathrm{CO} ; 2$.

Holland, M., 2003: The North Atlantic Oscillation-Arctic Oscillation in the CCSM2 and its influence on Arctic climate variability. J. Climate, 16, 2767-2781, doi:10.1175/1520-0442(2003)016<2767: TNAOOI $>2.0 . \mathrm{CO} ; 2$.

Hurrell, J. W., 1995: Decadal trends in the North Atlantic Oscillation: Regional temperatures and precipitation. Science, 269, 676-679, doi:10.1126/science.269.5224.676.

Itoh, H., 2008: Reconsideration of the true versus apparent Arctic Oscillation. J. Climate, 21, 2047-2062, doi:10.1175/2007JCLI2167.1.

Jones, J. W., J. W. Hansen, F. S. Royce, and C. D. Messina, 2000: Potential benefits of climate forecasting to agriculture. Agric. Ecosyst. Environ., 82, 169-184, doi:10.1016/S0167-8809(00)00225-5.

Kalra, A., W. P. Miller, K. W. Lamb, S. Ahmad, and T. Piechota, 2013: Using large-scale climatic patterns for improving long lead time streamflow forecasts for Gunnison and San Juan River basins. Hydrol. Processes, 27, 1543-1559, doi:10.1002/ hyp. 9236.

Kangas, R. S., and T. J. Brown, 2007: Characteristics of US drought and pluvials from a high-resolution spatial dataset. Int. J. Climatol., 27, 1303-1325, doi:10.1002/joc.1473.

Katz, R. W., M. B. Parlange, and C. Tebaldi, 2003: Stochastic modeling of the effects of large-scale circulation on daily weather in the southeastern U.S. Climatic Change, 60, 189216, doi:10.1023/A:1026054330406.

Lapp, S. L., J. St Jacques, E. M. Barrow, and D. J. Sauchyn, 2012: GCM projections for the Pacific decadal oscillation under greenhouse forcing for the early 21 st century. Int. J. Climatol., 32, 1423-1442, doi:10.1002/joc.2364.

Lau, N.-C., 1988: Variability of the observed midlatitude storm tracks in relation to low-frequency changes in the circulation pattern. J. Atmos. Sci., 45, 2718-2743, doi:10.1175/ 1520-0469(1988)045<2718:VOTOMS > 2.0.CO;2.

Leathers, D. J., B. Yarnal, and M. A. Palecki, 1991: The Pacific/North American teleconnection pattern and United States climate. Part I: Regional temperature and precipitation associations. J. Climate, 4, 517-528, doi:10.1175/1520-0442(1991)004<0517: TPATPA $>2.0 . \mathrm{CO} ; 2$. 
Linkin, M. E., and S. Nigam, 2008: The North Pacific OscillationWest Pacific teleconnection pattern: Mature-phase structure and winter impacts. J. Climate, 21, 1979-1997, doi:10.1175/ 2007JCLI2048.1.

McAfee, S. A., and J. L. Russell, 2008: Northern Annular Mode impact on spring climate in the western United States. Geophys. Res. Lett., 35, L17701, doi:10.1029/2008GL034828.

McCabe, G. J., and M. D. Dettinger, 2002: Primary modes and predictability of year-to-year snowpack variations in the western United States from teleconnections with Pacific Ocean climate. J. Hydrometeor., 3, 13-25, doi:10.1175/ 1525-7541(2002)003<0013:PMAPOY >2.0.CO;2.

_, M. A. Palecki, and J. L. Betancourt, 2004: Pacific and Atlantic Ocean influences on multidecadal drought frequency in the United States. Proc. Natl. Acad. Sci. USA, 101, 4136-4141, doi:10.1073/pnas.0306738101.

—, J. L. Betancourt, S. T. Gray, M. A. Palecki, and H. G. Hidalgo, 2008: Associations of multi-decadal sea-surface temperature variability with US drought. Quat. Int., 188, $31-$ 40, doi:10.1016/j.quaint.2007.07.001

McKee, T. B., N. J. Doesken, and J. Kleist, 1993: The relationship of drought frequency and duration to time scales. Preprints, Eighth Conf. on Applied Climatology, Anaheim, CA, Amer. Meteor. Soc., 179-184.

Meinke, H., and R. C. Stone, 2005: Seasonal and inter-annual climate forecasting: The new tool for increasing preparedness to climate variability and change in agricultural planning and operations. Climatic Change, 70, 221-253, doi:10.1007/ s10584-005-5948-6.

Meko, D. M., D. W. Stahle, D. Griffin, and T. A. Knight, 2011: Inferring precipitation-anomaly gradients from tree rings. Quat. Int., 235, 89-100, doi:10.1016/j.quaint.2010.09.006.

Mills, C. M., and J. E. Walsh, 2013: Seasonal variation and spatial patterns of the atmospheric component of the Pacific decadal oscillation. J. Climate, 26, 1575-1594, doi:10.1175/ JCLI-D-12-00264.1.

Mock, C., 1996: Climatic controls and spatial variations of precipitation in the western United States. J. Climate, 9, 1111-1125, doi:10.1175/1520-0442(1996)009<1111:CCASVO > 2.0.CO;2

Moen, J., 2008: Climate change: Effects on the ecological basis for reindeer husbandry in Sweden. Ambio, 37, 304-311, doi:10.1579/0044-7447(2008)37[304:CCEOTE]2.0.CO;2.

Moore, G. W. K., I. A. Renfrew, and R. S. Pickart, 2013: Multidecadal mobility of the North Atlantic Oscillation. J. Climate, 26, 2453-2466, doi:10.1175/JCLI-D-12-00023.1.

Osborn, T. J., 2011: Winter 2009/2010 temperatures and a recordbreaking North Atlantic Oscillation index. Weather, 66, 19-21, doi:10.1002/wea.660.

Redmond, K. T., and R. W. Koch, 1991: Surface climate and streamflow variability in western United States and their relationship to large-scale circulation indices. Water Resour. Res., 27, 2381-2399, doi:10.1029/91WR00690.

Revkin, A., 2010: Clashing Pacific and Atlantic patterns shaped super snows. New York Times, 27 July. [Available online at http://dotearth. blogs.nytimes.com/2010/07/27/clashing-pacific-and-atlantic-patternsshaped-super-snows.]

Rodionov, S., and R. Assel, 2000: Atmospheric teleconnection patterns and severity of winters in the Laurentian Great Lakes basin. Atmos.-Ocean, 38, 601-635, doi:10.1080/ 07055900.2000 .9649661$.
Rodó, X., and Coauthors, 2013: Climate change and infectious diseases: Can we meet the needs for better prediction? Climatic Change, 118, 625-640, doi:10.1007/s10584-013-0744-1.

Ropelewski, C. F., and P. D. Jones, 1987: An extension of the Tahiti-Darwin Southern Oscillation index. Mon. Wea. Rev., 115, 2161-2165, doi:10.1175/1520-0493(1987)115<2161: AEOTTS $>2.0 . \mathrm{CO} ; 2$

Roylance, F. D., 2010: Cold? Blame the North Atlantic Oscillation. Baltimore Sun, 9 January. [Available online at http://articles. baltimoresun.com/2010-01-09/news/1001080125_1_baltimorewinter-cold-el-nino.]

Seager, R., Y. Kushnir, J. Nakamura, M. Ting, and N. Naik, 2010: Northern Hemisphere winter snow anomalies: ENSO, NAO and the winter of 2009/10. Geophys. Res. Lett., 37, L14703, doi:10.1029/2010GL043830.

Seierstad, I. A., D. B. Stephenson, and N. G. Kvamstǿ, 2007: How useful are teleconnection patterns for explaining variability in extratropical storminess? Tellus, 59A, 170-181, doi:10.1111/ j.1600-0870.2007.00226.x.

Shinker, J. J., P. J. Bartlein, and B. Shuman, 2006: Synoptic and dynamic climate controls of North American mid-continental aridity. Quat. Sci. Rev., 25, 1401-1417, doi:10.1016/j.quascirev.2005.12.012.

Sinha, T., and A. Sankarasubramanian, 2013: Role of climate forecasts and initial conditions in developing streamflow and soil moisture forecasts in a rainfall-runoff regime. Hydrol. Earth Syst. Sci., 17, 721-733, doi:10.5194/hess-17-721-2013.

Thomson, A. J., 2010: Climate indices, rainfall onset and retreat, and malaria in Nigeria. J. Vector Borne Dis., 47, 193-203. [Available online at http://www.mrcindia.org/journal/issues/ 474193.pdf.]

Thomson, M. C., F. J. Doblas-Reyes, S. J. Mason, R. Hagedorn, S. J. Connor, T. Phindela, A. P. Morse, and T. N. Palmer, 2006: Malaria early warnings based on seasonal climate forecasts from multi-model ensembles. Nature, 439, 576-579, doi:10.1038/nature04503.

Wallace, J. M., and D. S. Gutzler, 1981: Teleconnections in the geopotential height field during the Northern Hemisphere winter. Mon. Wea. Rev., 109, 784-812, doi:10.1175/ 1520-0493(1981)109<0784:TITGHF>2.0.CO;2.

Wedgbrow, C. S., R. L. Wilby, H. R. Fox, and G. O'Hare, 2002: Prospects for seasonal forecasting of summer drought and low river flow anomalies in England and Wales. Int. J. Climatol., 22, 219-236, doi:10.1002/joc.735.

Werritty, A., 2002: Living with uncertainty: Climate change, river flows and water resource management in Scotland. Sci. Total Environ., 294, 29-40, doi:10.1016/S0048-9697(02)00050-5.

Wise, E. K., 2010: Spatiotemporal variability of the precipitation dipole transition zone in the western United States. Geophys. Res. Lett., 37, L07706, doi:10.10292009GL042193.

Woollings, T., A. Hannachi, and B. Hoskins, 2010: Variability of the North Atlantic eddy-driven jet stream. Quart. J. Roy. Meteor. Soc., 136, 856-868, doi:10.1002/qj.625.

Wu, H., M. D. Svoboda, M. J. Hayes, D. A. Wilhite, and F. Wen, 2007: Appropriate application of the standardized precipitation index in arid locations and dry seasons. Int. J. Climatol., 27, 65-79, doi:10.1002/joc.1371.

Zhang, T., J. Perlwitz, and M. P. Hoerling, 2014: What is responsible for the strong observed asymmetry in teleconnections between El Niño and La Niña? Geophys. Res. Lett., 41, 1019-1025, doi:10.1002/2013GL058964. 